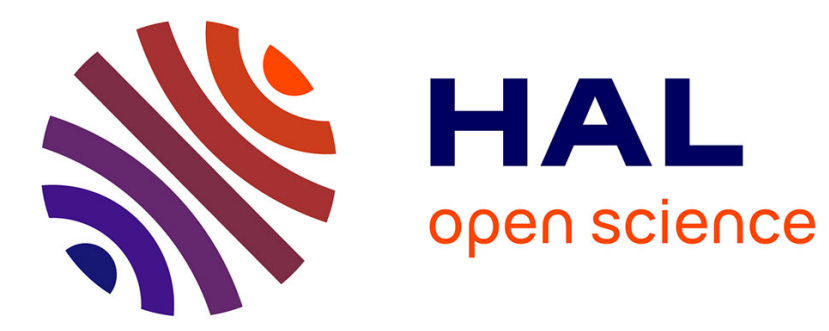

\title{
Optimized fuzzy rule-based energy management for a battery-less PV/wind-BWRO desalination system
}

Ines Ben Ali, Mehdi Turki, Jamel Belhadj, Xavier Roboam

\section{To cite this version:}

Ines Ben Ali, Mehdi Turki, Jamel Belhadj, Xavier Roboam. Optimized fuzzy rule-based energy management for a battery-less PV/wind-BWRO desalination system. Energy, 2018, 159, pp.216-228. 10.1016/j.energy.2018.06.110 . hal-02330729

\section{HAL Id: hal-02330729 \\ https://hal.science/hal-02330729}

Submitted on 24 Oct 2019

HAL is a multi-disciplinary open access archive for the deposit and dissemination of scientific research documents, whether they are published or not. The documents may come from teaching and research institutions in France or abroad, or from public or private research centers.
L'archive ouverte pluridisciplinaire HAL, est destinée au dépôt et à la diffusion de documents scientifiques de niveau recherche, publiés ou non, émanant des établissements d'enseignement et de recherche français ou étrangers, des laboratoires publics ou privés. 


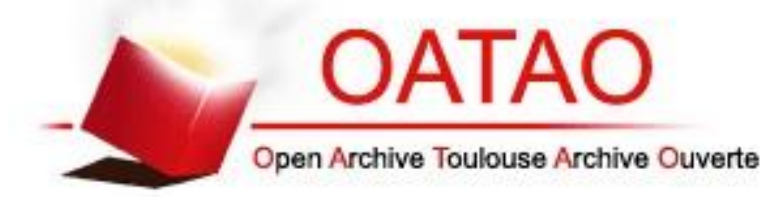

Open Archive Toulouse Archive Ouverte

OATAO is an open access repository that collects the work of Toulouse researchers and makes it freely available over the web where possible

This is an author's version published in: http://oatao.univ-toulouse.fr/24159

\section{Official URL:}

https://doi.org/10.1016/j.energy.2018.06.110

\section{To cite this version:}

Ben Ali, Ines and Turki, Mehdi and Belhadj, Jamel and Roboam, Xavier Optimized fuzzy rule-based energy management for a battery-less PV/wind-BWRO desalination system. (2018) Energy, 159. 216-228. ISSN 0360-5442

Any correspondence concerning this service should be sent to the repository administrator: tech-oatao@listes-diff.inp-toulouse.fr 


\title{
Optimized fuzzy rule-based energy management for a battery-less PV/ wind-BWRO desalination system
}

\author{
I. Ben Ali ${ }^{\text {a }}$, M. Turki ${ }^{\text {a, b }}$, J. Belhadj ${ }^{\text {a, c, }{ }^{*}, \text { X. Roboam }}{ }^{\text {d }}$ \\ a Université de Tunis El Manar, LR 11 ES 15, Laboratoire des Systemes Électriques, École Nationale d'Ingénieurs de Tunis, BP 37, 1002, Tunis le Belvédere, \\ Tunis, Tunisia \\ ${ }^{\mathrm{b}}$ Université de Jendouba, École Supérieure des Ingénieurs de Medjez El Bab, P5, 9070, Tunisia \\ ${ }^{c}$ Université de Tunis, École Nationale Supérieure d'Ingénieurs de Tunis, BP 56, 1008, Montfleury, Tunisia \\ ${ }^{\mathrm{d}}$ Université de Toulouse, LAPLACE (Laboratoire Plasma et Conversion d'Énergie), UMR CNRS-INP-UPS, ENSEEIHT, 2 Rue Camichel, 31071, Toulouse, France
}

Keywords:

Water/energy production

Renewable energy sources

Energy management

Fuzzy logic

Genetic algorithm optimization

\begin{abstract}
A B S T R A C T
Coupling water desalination processes with Renewable Energy Sources (RESs) can be a sustainable and ecological approach to the global water/energy supply crisis. In this regard, small scale standalone battery less Brackish Water Reverse Osmosis (BWRO) desalination system powered by a hybrid PV/Wind RES is expected to meet freshwater demand of a small isolated community. One particularity of the proposed architecture deals with the absence of electrochemical storage; only taking benefit of hydraulic storage in water tanks when RE is available. This study puts forward the prime importance of Water/ Power flows management optimization. For this purpose, an online Fuzzy Logic based Energy Manage ment Strategy (FLEMS) is proposed. Firstly, a Hand Made Fuzzy Inference System (HMFIS) was designed to identify the instantaneous power sharing between the system hydro mechanical processes (well pumping, water storage and desalination processes). Secondly, an offline genetic algorithm optimization was applied on the HMFIS design in order to optimize the power sharing factor and maximize freshwater production. Then, when applying unknown power profile, the optimized FLEMS demonstrated its per formance to improve the system energy efficiency and enhance the brackish water (from $16.7 \%$ in autumn to $63 \%$ in summer) and freshwater production (to $3.3 \%$ during autumn for instance) compared with the HMFIS based EMS.
\end{abstract}

\section{Introduction}

A rapid growth in worldwide energy demand, a high variability of primary fossil fuels prices (oil, gas ... etc.), a very worrying climate change, an unavoidable depletion of water and oil supplies have led to the global awareness during this century, in particular of our planet capacity limits [1]. Given the current situation, the ever growing population and the global warming, the integration of ecological factor in the design of energy generation systems is increasingly important so as to decrease green gas emissions from fossil fuels. Otherwise, freshwater scarcity is more and more increasing all over the world. Indeed, 1.1 billion people worldwide

\footnotetext{
* Corresponding author. Université de Tunis, École Nationale Supérieure d'Ingénieurs de Tunis, BP 56 1008, Montfleury, Tunisia.

E-mail addresses: ines.benali.lse@gmail.com (I. Ben Ali), mehdi_turki1@yahoo.fr (M. Turki), Jamel.Belhadj@esstt.rnu.tn (J. Belhadj), Xavier.Roboam@laplace.univ-
} tlse.fr (X. Roboam). currently live in areas with no access to water and by 2025 two thirds of the world's population may face water scarcity [2,3]. Generally, regions suffering from lack of freshwater are also suffering from electrical facilities missing. For this issue, the use of water desalination systems supplied with Renewable Energy Sources (RESs) is of great interest and has become an essential requirement in these regions. Coupling between Reverse Osmosis (RO) desalination systems and RESs, specifically photovoltaic en ergy and wind turbines, is widely spread [4,5] due to its advantages. The main advantages of the RO technique consist on lower energy consumption over other desalination techniques [6] as well as less maintenance need [7]. Moreover, photovoltaic panels and wind turbines have normally a long lifetime and low maintenance cost [8], as well as they give a sustainable and environment friendly alternative over conventional energy sources [9,10]. Otherwise, employing RESs with storage batteries presents many advantages, namely providing constant energy flow during insufficient energy production time and the ability to buffer the energy production 


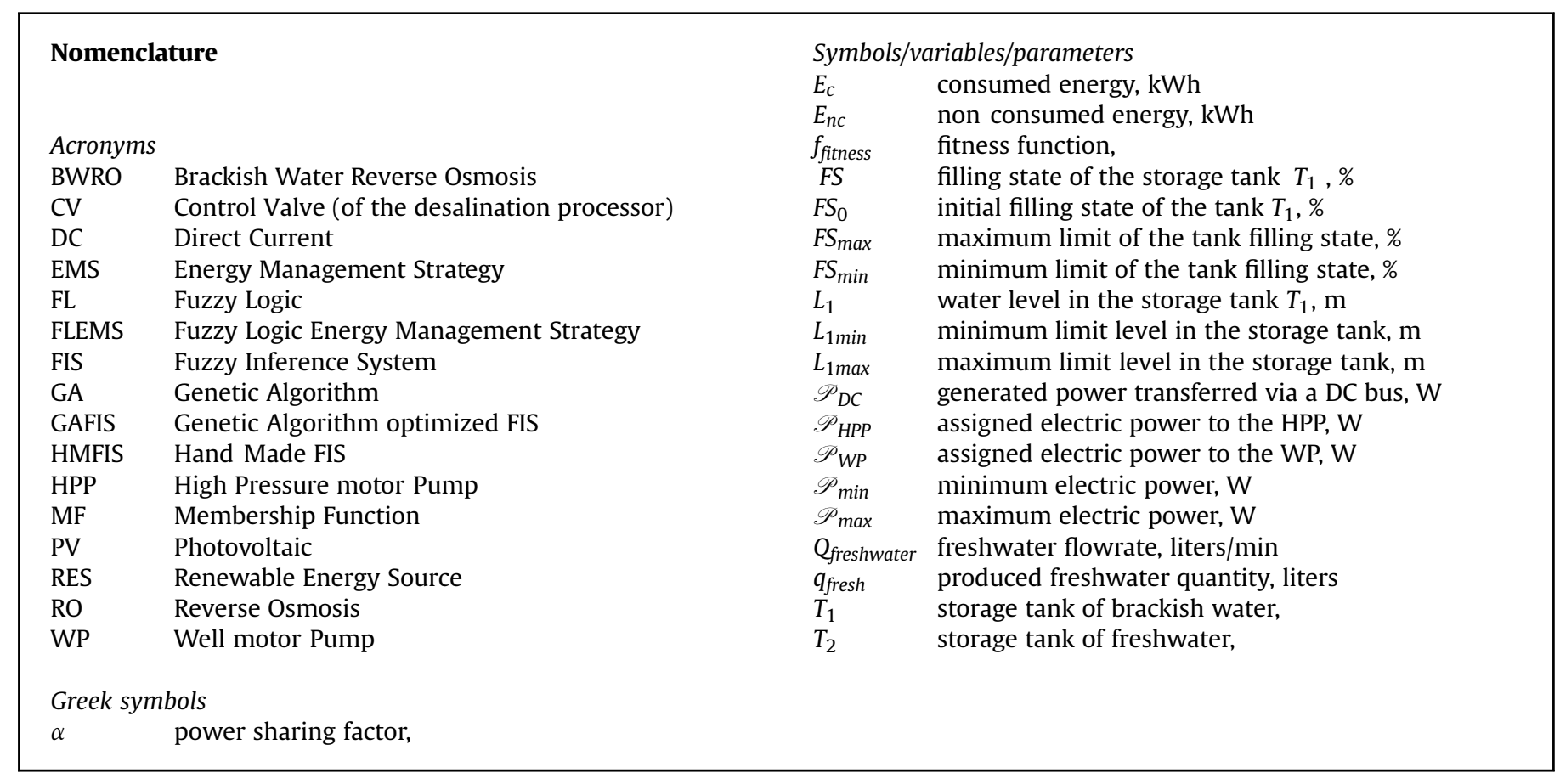

variations. However, the cost and maintenance of batteries is often a major concern. Therefore, minimizing or even suppressing elec trochemical storage devices should be a challenge. It has been shown in previous research that the operation of the RO membrane under variable power supply (i.e. variable feed flows and pressures) remains unaffected [11,12]. In this context, a focus on a specific class of standalone small scale BWRO desalination system without electrochemical storage device is put forward in this paper. Then, in order to utilize this optimally in such an autonomous system, a specific power and water flows management is required. For our case study, the main idea is to take advantage of hydraulic storage in water tanks instead of electrochemical storage through exploit ing motor pumps modularity versus the given generated power (i.e. several pumping subsystems that can be switched on/off). Thus, the given intermittent power has to be instantaneously shared in all hydro mechanical processes using an optimized Energy Manage ment Strategy (EMS) in order to maximize the freshwater pro duction following weather conditions while considering the whole system constraints.

It is demonstrated in literature that Fuzzy Inference System (FIS) is appropriate for control and EMS in complex energy systems namely:

- Transport domain, such as Hybrid Electric Vehicles (HEVs) [13,14] electric bus [15], aircraft [16], railway traction [17],

- Micro grids [18,19], and RESs [20,21],

- Water pumping [22] and desalination systems [23].

Just to name a few: ref [13] and [14] showed some examples of optimal fuzzy EMS for HEVs, whose objective was to find the optimal instantaneous power distribution between the different energy sources in the HEV. In Ref. [16], the authors presented four EMSs for a local power distribution system of more electric aircraft. The proposed EMSs are based on two multi objective strategies using Fuzzy Logic (FL) and two simpler mono objective strategies (such as PI controller). Simulation and experimental results demonstrated that FL is appropriate for multi objective ap proaches, processing a large number of input variables and integrating several constraints. Moreover, ref [18] presented and evaluated a fuzzy hourly EMS for a stand alone HRES (Hybrid Renewable Energy System). It is developed to meet the demanded power of a stand alone house situated in Álora (Malaga Spain) and maintain the hydrogen tank level and the battery SOC within a certain target margins, while ensuring the optimization of both the utilization cost and the energy storage system lifetime. In this work, simulation results showed that the proposed fuzzy EMS meets the established objectives and reaches 13\% total cost saving over another simpler control states based EMS presented in that paper.

Regarding water desalination systems, EMSs have to solve the same problems as mentioned above since they have to deal with almost the same constraints, criteria and objectives. It is quite specific in terms of constraints but it has to face the same chal lenges, namely: producing freshwater to meet population demands for a given variable power generation while respecting the system constraints. Although there is a great deal of research [24] and techno economic studies [6] in order to promote coupling desali nation technologies with renewable energy systems $[25,26]$ in or der on the one hand to reduce energy/water costs [27] and, on the other hand to ensure power supply for desalination units in remote regions [28] in an environmentally friendly manner [9,10], Research on energy management of such desalination systems are limited in literature. Some previous research on energy management field of desalination systems with different methods can be found in the literature and are described below.

In Ref. [29], the authors have proposed an energy management strategy using standard nonlinear programming methods to a battery less BWRO desalination system including three motor pumps, RO desalination process, and three water storage tanks. The issue is to reduce the needed filling time of the third tank. Five different objective functions are proposed and compared in terms of robustness and performances where the evaluation criterion is the needed time to fill the three tanks.

Ref [30] has introduced an energy management strategy that can be applied in the case of power and freshwater generation. The approach is based on mathematical optimization model (mathe matical linear programming) that takes into account random 
variations in demand and energy supply. The model is solved for the case of Saudi Arabia with the objective of minimizing the total costs for generating water and power while reducing the uncer tainty impact in the environment.

In Ref. [31], a real time energy management system based on rolling horizon strategy for different operation modes has been proposed for stand alone micro grid consisting of diesel genera tion, wind turbine generation, an energy storage system, and a sea water desalination system. It is based on hourly wind forecast. Experimental results have evidenced that the energy management system can recognize system operation mode online, and suc cessfully achieve the function of switching operation modes ac cording to the predicted wind speed, batteries state of charge, and so on.

Finally, a variable load EMS based on Fuzzy Cognitive Maps (FCM) has been developed in Ref. [32]. Then, an ON OFF EMS based on hysteresis control scheme has been considered for comparison purpose with the first EMS: the yearly freshwater production has been compared. The system consists of an already installed PV/RO desalination system with battery bank in an island in the Cyclades complex (Aegean Sea of Greece). Two case studies for the same system have been investigated by acting on the capacity factor of the desalination system. The obtained results have evidenced that an upgrade to a variable load operation scheme leads to consider able increase in the freshwater production from the same system ranging from nearly $41 \%$ for the first case study to nearly $54 \%$ for the second.

Based on the above state of the art, two points are highlighted:

- Fuzzy logic has been successfully used for energy management of complex energy systems with the advantage of easy optimi zation of its parameters design.

- Control and supervisory approaches are not the same when operating a desalination unit with renewable energy system including or without batteries. Battery less systems passively operates according to the generated energy by renewable en ergy systems leading to a variable operation in desalination units.

Given the limited energy management studies of battery less PV/Wind BWRO desalination systems in literature, we propose in this work a real time EMS, where a fuzzy decision maker algorithm using the fuzzy logic theory will be integrated. The decision making for the power sharing between the hydro mechanical subsystems mainly depends on two input variables that are the given generated electric power and the water storage tank states. The proposed strategy lies in two steps. The first one is to design a FIS that is based on a logical analysis phase performed and detailed in our previous work [33,34]. The latter enabled us to acquire "in depth system knowledge", thus making a base of energy manage ment expertise. Through this phase, we have determined what must be done during the system operation, for a given operation condi tion, enabling us to define a useful fuzzy rule base oriented by operation modes dependence. In the second step, a Genetic Algo rithm (GA) will be used for offline optimization of the FIS's param eters including Membership Functions (MFs), fuzzy rules and Defuzzification method. Being implemented in the EMS, the GA optimized design has been assessed and compared with the initial design in terms of robustness and performances.

\section{BWRO system specifications}

The studied BWRO desalination system is dedicated to meet freshwater demand of a small community in remote areas with no access to freshwater and electrical grids, but where renewable energy resources are abundant. The system consists of small scale standalone brackish water pumping and desalination application supplied with a variable generated power offered along wind speed and solar irradiation conditions without battery storage. But before implementing such an autonomous system we have to investigate its feasibility in the first instance. For this sake, an experimental BWRO desalination test bench has been designed and implemented in our research laboratory where its freshwater production is rated at $300 \mathrm{l} / \mathrm{h}$ (Fig. 1 and Table 1). This experimental test bench is powered by a programmable DC power source rated at $4 \mathrm{~kW}$ which physically emulates the power produced by the RES. The given variable power $\mathscr{P}_{D C}$ is transferred via a DC bus to the hydro mechanical processes of the BWRO test bench.

The first hydro mechanical subsystem (water pumping process) is dedicated to water conveyance from the brackish water well to an elevated storage tank $\left(T_{1}\right)$ using a single stage motor pump (Well Pump (WP)) rated at $0.75 \mathrm{~kW}$ (Fig. 2). The storage tank $\left(T_{1}\right)$ is $2180 \mathrm{~L}$ capacity, $1.15 \mathrm{~m}$ diameter and $2.10 \mathrm{~m}$ height. Indeed, water is a very good storage medium. Therefore, brackish water can be simultaneously pumped and desalinated when the energy supply is available and abundant, and be stored when it is not. This may alleviate the expensive buck up systems need in remote areas with good renewable energy resources. The second hydro mechanical subsystem (RO desalination process) is devoted to producing freshwater through a BWRO desalination process consisting of a multi stage High Pressure motor Pump (HPP), rated at $2.2 \mathrm{~kW}$, feeding a single RO membrane (TORAY TM710). Within this configuration, the 'gravitational water storage' involves an advan tage of great importance in terms of energy efficiency improvement.

\section{Energy management strategy (EMS)}

\subsection{EM problem definition}

The existence of two hydro mechanical subsystems imposes to utilize an EMS for determining the appropriate power sharing be tween these subsystems with respect to the given power, the cur rent filling state of the storage tank, and their hydraulic characteristics. For this purpose, we try to resolve the problem such

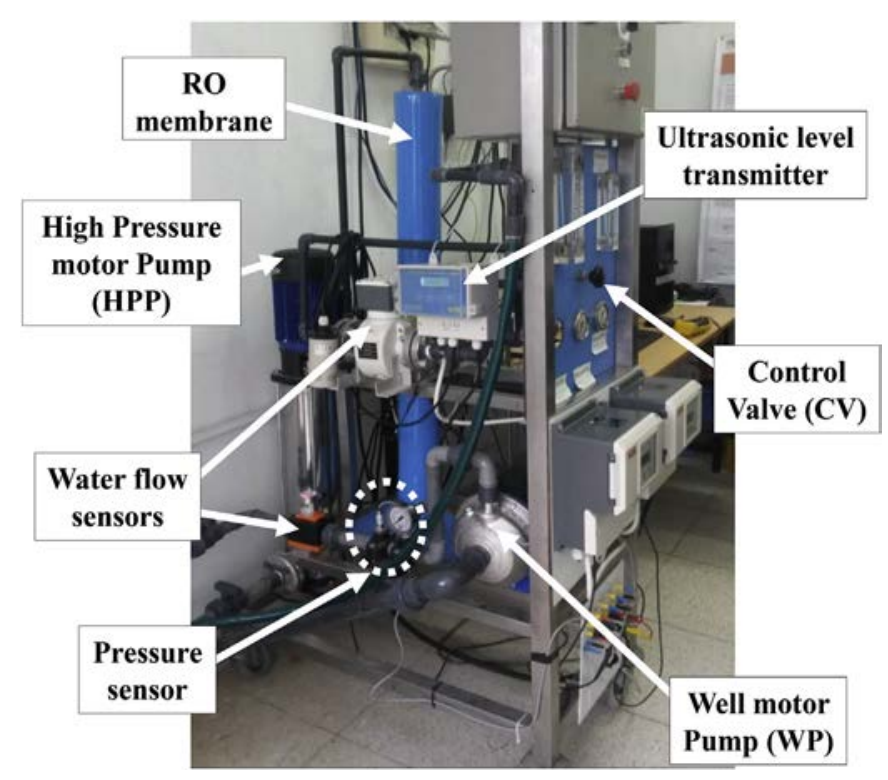

Fig. 1. BWRO desalination experimental test bench. 
Table 1

Characteristics of the main unit elements.

\begin{tabular}{ll}
\hline Elements & Main characteristics \\
\hline High Pressure Pump (HPP) & Power output: $2,2 \mathrm{~kW}$ \\
& Operating Pressure: $8,17 \quad 18,6 \mathrm{bar}$ \\
& Maximum flow rate: $60 \mathrm{l} / \mathrm{min}$ \\
Well Pump (WP) & Power output: $0,75 \mathrm{~kW}$ \\
& Operating Pressure: $2,5 \quad 3,4 \mathrm{bar}$ \\
& Maximum flow rate: $90 \mathrm{l} / \mathrm{min}$ \\
RO membrane & Maximum freshwater production: $300 \mathrm{l} / \mathrm{h}$ \\
Storage tank $\left(T_{1}\right)$ & Capacity: $2180 \mathrm{~L}$ \\
\hline
\end{tabular}

as how to manage simultaneously the power and water flows while fulfilling technological (power range of motor pumps) and func tional (tank filling state) constraints during the system operation?

To answer this question, we have set a management strategy allowing instantaneously determining the power sharing between the two hydro mechanical processes according a power sharing factor $(\alpha)$ given by:

$$
\left\{\begin{array}{cc}
\mathscr{P}_{H P P} \quad \alpha \cdot \mathscr{P}_{D C} \\
\mathscr{P}_{W P}\left(\begin{array}{ll}
1 & \alpha
\end{array}\right) \cdot \mathscr{P}_{D C}
\end{array}\right.
$$

Note that this simplified case study limits the approach to 2 hydro mechanical devices, but the methodology may be extrapo lated to any number of subsystems.

\subsection{EM criteria and constraints}

Based on experimental characterization, a whole and accurate understanding of the studied system has been acquired [33,35]. The decision making is made on the basis of constraints of the system elements and criterion (maximizing freshwater production).

So, given a hydraulic load characteristic, the suitable power range $\left[\begin{array}{ll}\mathscr{P}_{\min } & \mathscr{P}_{\text {max }}\end{array}\right]$ of each pumping device has been experi mentally identified. Indeed, we have determined the suitable hy draulic load characteristic allowing us to achieve a water production/efficiency trade off (Fig. 3 and Fig. 4). This is considered a first step to prepare the prerequisites for an effective EMS.

According to these experiments, the hydro mechanical pro cesses constraints are summarized in Table 2 . It should be noted that these values are corresponding to $4 \mathrm{~g} / \mathrm{l}$ as brackish water salinity and to $4 \mathrm{~m}$ storage tank elevation.

Moreover, from power ranges of motor pumps, three operating modes are considered for our system: water Pumping $(P)$, water Desalination (D), and both Pumping and Desalination (D\&P) modes $[33,36]$. The operating mode preference essentially depends on the variable power supply $\mathscr{P}_{D C}$, the stored water level $L_{1}$ in the tank $T_{1}$ that must vary on its specified confines $\left(L_{1 \min } \leq L_{1} \leq L_{1 \max }\right)$, and the operating power ranges of the two processes $\left[\mathscr{P}_{\min } \mathscr{P}_{\max }\right]$ (Fig. 5). According to these data, the decision making regarding the power sharing - that is, how much should each motor pump absorb, becomes more difficult especially when the input power value and/or the tank water level is near limit thresholds or into an overlap area of power. In this regard, fuzzy logic theory can be the suitable approach for such a power sharing problem.

Note that in this work we did not consider the second tank $\left(T_{2}\right)$ constraints in the EMS, it can be considered as an infinite fresh water storage tank. This is another factor of interest consisting of the storage capacity of freshwater. It is possible to produce and store freshwater in large quantities for long periods of time when the energy supply is available, for use when energy supply drops.

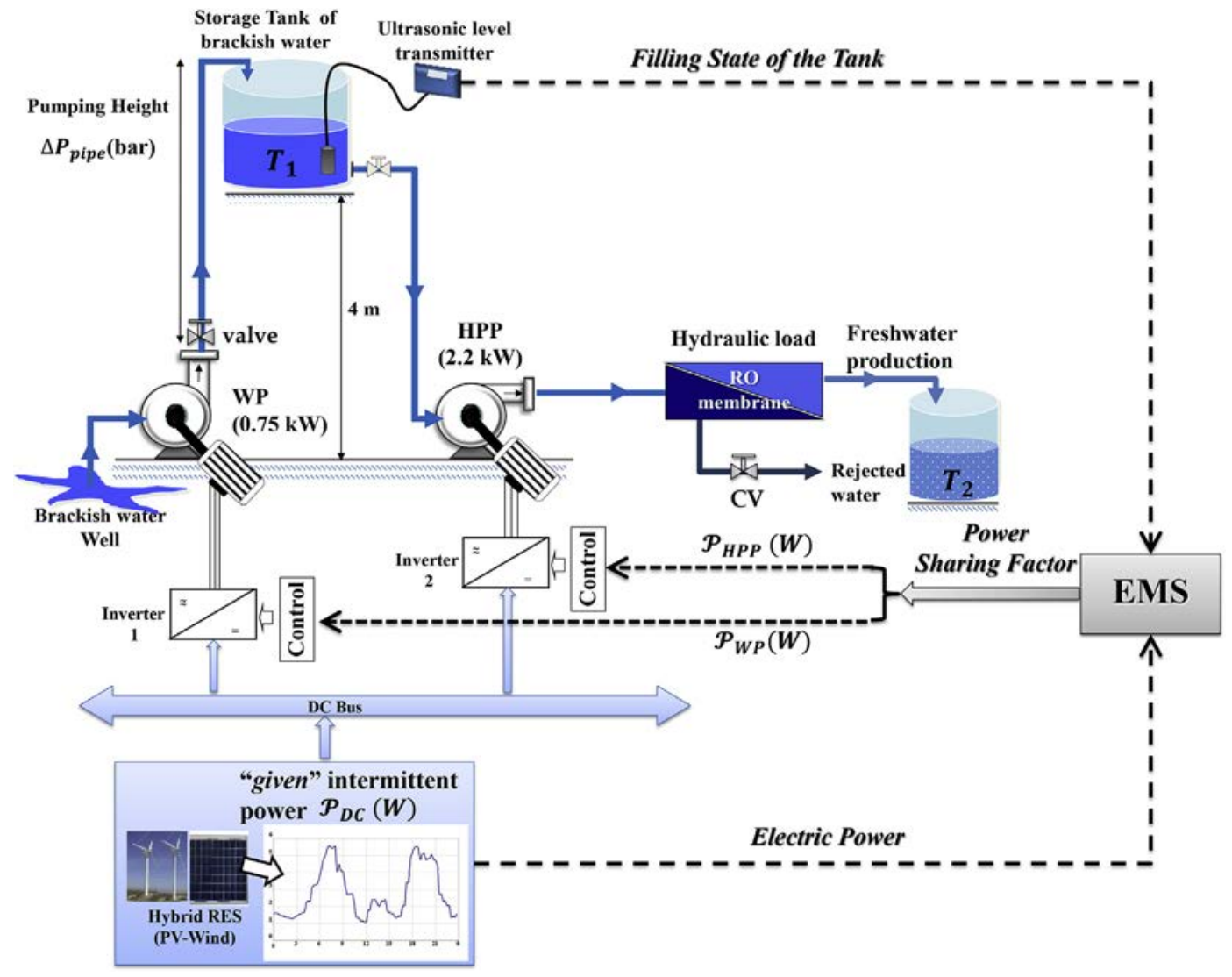

Fig. 2. Synoptic of the autonomous BWRO desalination system with its EMS. 

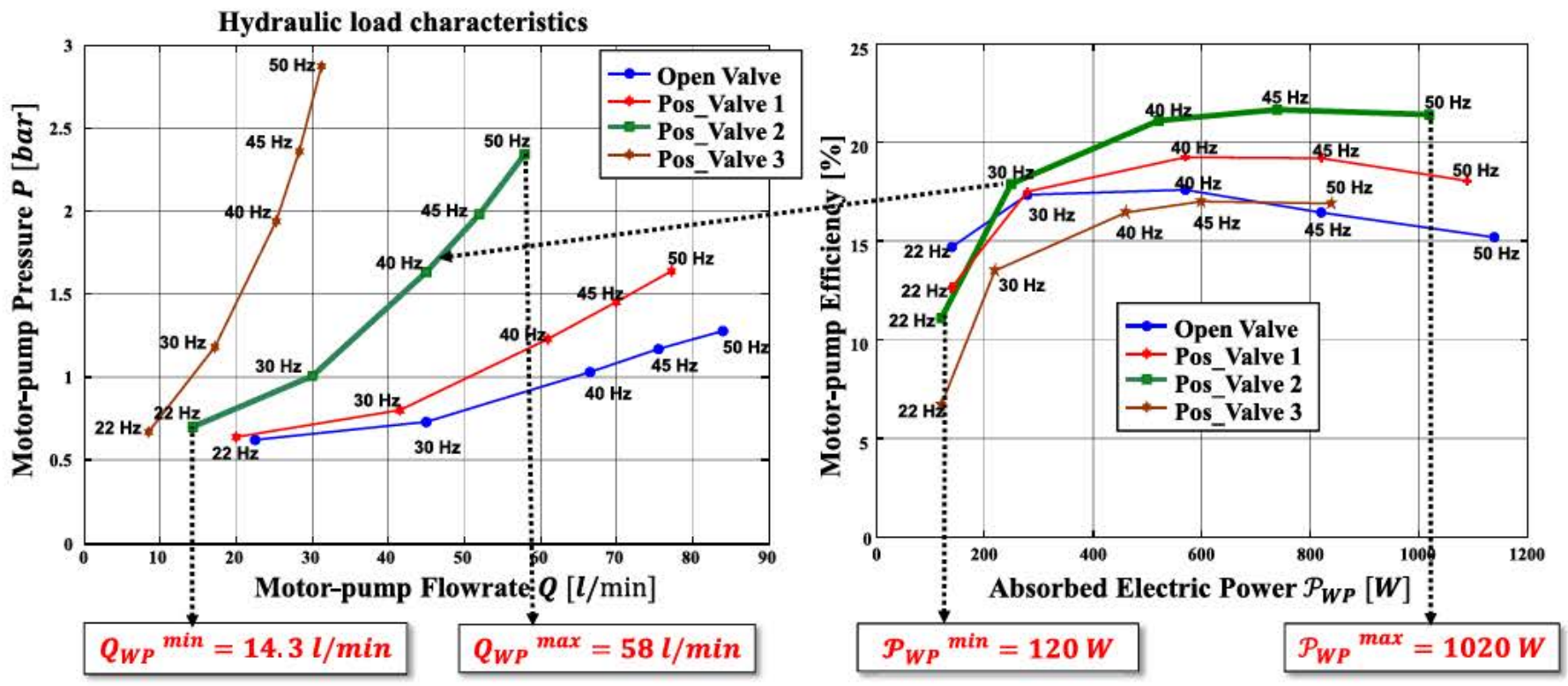

Fig. 3. Experimental characterization of the water pumping process.
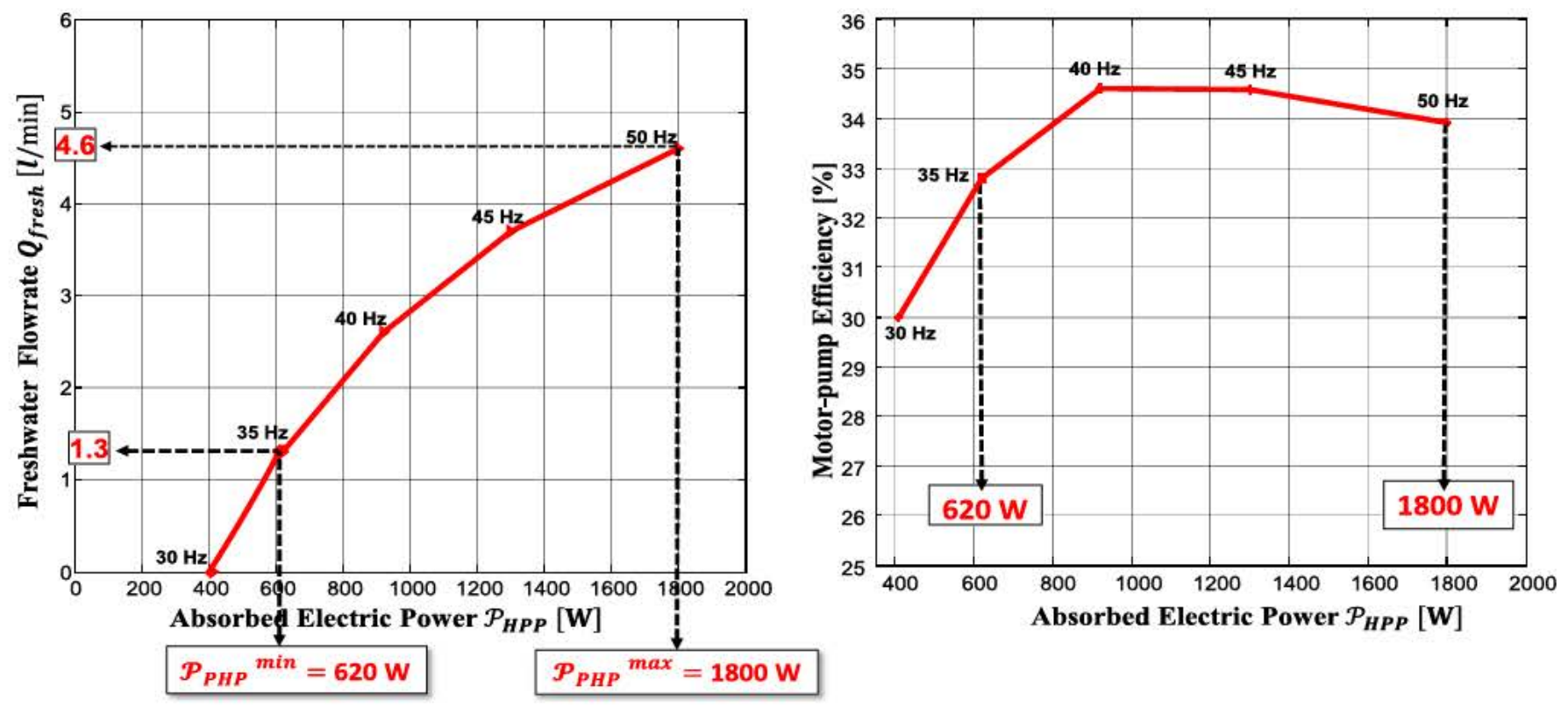

Fig. 4. Experimental characterization of the RO desalination process for brackish water salinity of $4 \mathrm{~g} / \mathrm{l}$.

Table 2

System constraints.

\begin{tabular}{|c|c|c|c|c|c|}
\hline \multicolumn{2}{|c|}{ Well Pump } & \multicolumn{2}{|c|}{ HP Pump } & \multicolumn{2}{|c|}{ Tank water level } \\
\hline $\begin{array}{l}\mathscr{P}_{\text {WPmin }} \\
\mathscr{P}_{\text {WPmax }}\end{array}$ & $\begin{array}{l}120 W \\
1020 \mathrm{~W}\end{array}$ & $\begin{array}{l}\mathscr{P}_{\text {HPPmin }} \\
\mathscr{P}_{\text {HPPmax }}\end{array}$ & $\begin{array}{l}620 W \\
1800 W\end{array}$ & $\begin{array}{l}L_{1 \min } \\
L_{1 \max }\end{array}$ & $\begin{array}{l}0,2 \mathrm{~m} \\
2 \mathrm{~m}\end{array}$ \\
\hline
\end{tabular}

After having set the energy management problem and defining the system criteria and constraints, we will introduce and study the proposed EMS in the following sections.

\section{Fuzzy logic energy management strategy (FLEMS)}

The Fuzzy Inference System (FIS) is essential to manage effi ciently water and power flows in the system. The main objective that must be considered when designing the FIS is to maximize freshwater production of the desalination system according to the input electric power $\mathscr{P}_{D C}$ and the current Filling State $(F S)$ of the $\operatorname{tank} T_{1}$ (given $F S(\%) \quad \frac{L_{1}}{L_{1}} \cdot 100$ ). The designing phase of the FIS has been performed in two steps that will be described hereinafter.

\subsection{Hand - made FIS (HMFIS) - step 1}

In this study, we have designed a two inputs-single output FIS where the given DC power $\left(\mathscr{P}_{D C}\right)$ and theFS of the tank are defined as the FIS inputs and the power sharing factor $(\alpha)$ as the output. The designed FIS is based on "Mamdani" architecture and uses the "Centroid" method for Defuzzification giving a crisp output value. This method is considered as the most popular Defuzzification method which returns the centroid of area under curve. The chosen 

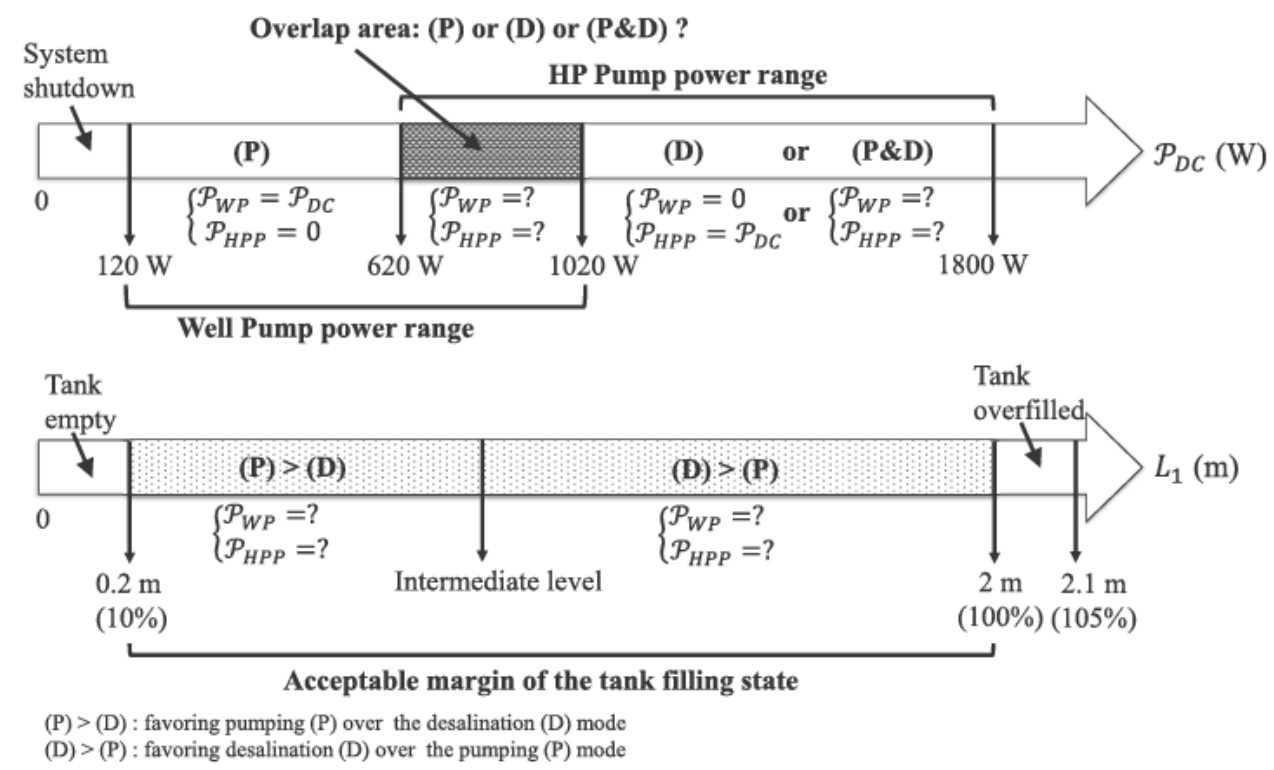

Fig. 5. Operating mode preference according the input electric power and the stored water level.

Membership Functions (MFs) of inputs and output are illustrated in Fig. 6. Triangle MFs are chosen to represent the FIS output and most of the two inputs. Nevertheless, we have chosen trapezoid shape to represent the first and the last MFs for the two inputs.

The presented FIS has been designed as follows: The first fuzzy input (the given DC power $\mathscr{P}_{\mathrm{DC}}$ ) is divided according to the oper ating power range of the two motor pumps into six fuzzy subsets represented by six MFs as follows: $\mathrm{QL}, \mathrm{L}, \mathrm{M}, \mathrm{QH}, \mathrm{H}$ and $\mathrm{VH}$. The range of values varies from 0 to $4000 \mathrm{~W}$ as the universe of discourse. The numerical range and the acronyms description of each fuzzy subset are given in Table 3 . The second fuzzy input determining the $F S$ of the storage tank is divided into five fuzzy subsets represented by five MFs as follows: E, L, M, F and OF (Table 3). Its universe of discourse is within the range of $0-105 \%$. Indeed, the tank is $2.1 \mathrm{~m}$ height corresponding to $105 \%$ value since we have defined the maximum storage limit $\left(L_{1 \max } \quad 2 \mathrm{~m}\right)$ as $100 \%$. Actually, the upper $0.1 \mathrm{~m}$ is reserved to avoid tank overflow. As for the fuzzy output, it represents the power sharing factor enabling to instantaneously share the current power $\mathscr{P}_{D C}$ over the two motor pumps according to equation (1). The fuzzy output is divided into five fuzzy subsets denoted as follows: OFF, A, B, C and D (Table 3). Where, the first subset (OFF) causes the HP motor pump (HPP) shutdown. The rest of the fuzzy subsets involve its operation, from the subset (A) which limits the use of the HPP to a moderate ratio, until quasi exclusively favoring desalination (D) over the pumping mode. The output universe of discourse is within the range of $0-1$.

In fuzzy inference systems, inputs are related to outputs by "if then" linguistic rules making possible to transcribe in a simple way the expertise (the human know how) acquired regarding the stud ied system. So, the fuzzy rule base (30 rules), summarized by the decision matrix shown in Table 4, are based on previous under standing of the system. Rule base is determined so that motor pumps operate on their optimal efficiency region and tank FS var ies on its specified confines with the purpose of maximizing the freshwater production. For instance, in case of Low power gener ation [" $\mathscr{P}_{D C}(i)$ is L"] and if the storage tank is Full ["FS(i) is F"], we must take advantage of all the generated power for only water desalination, therefore [" $\alpha(i)$ is D"] (i.e. $\mathscr{P}_{\text {HPP }}(i)$ $\left.\alpha \cdot \mathscr{P}_{D C}(i) \cong \mathscr{P}_{D C}(i)\right)$. This leads to the following rule:

IF $\mathscr{P}_{D C}$ is L AND FS is F THEN $\alpha$ is D.
In other case, if the power generation is abundant (Quite High) [" $\mathscr{P}_{D C}(i)$ is $Q H$ "] and if the water level in the tank is Low ["FS(i) is L"], we must take advantage of the abundant generated power to thoroughly desalinate the available amount of stored water while respecting the secure limit $\left(L_{1 \mathrm{~min}}\right)$ of the storage tank. This leads to the following rule:

IF $\mathscr{P}_{D C}$ is QH AND FS is L THEN $\alpha$ is D.

It should be noted that designing phase of the FIS consists of the choice of its characteristic parameters, namely the number and shapes (type) of MFs per input/output and the location of their characteristic points, the fuzzy rules, and finally the Defuzzification method. This phase is essentially based on hand and iterative adjustment trials and expert analyses of obtained results in order to improve the FIS design with the purpose of maximizing the freshwater production in our case study. So, first of all we set the initial FIS design by setting the MF of inputs/outputs variables (number, type, location and mapping) and setting the initial rule base and the Defuzzification method. Then, we try each time to adjust the inputs/outputs parameters of the MFs while adjusting the rule base as well as the Defuzzification method. Nevertheless, it is very difficult to find an optimal combination of these character istic parameters. Indeed, each choice of setting parameters results a new different FIS affecting the EMS performances. The best possible solution provides better power sharing but needs lots of human expertise and a huge number of tests to be found. Therefore, in order to find an optimal FIS and limit adjustment trials time, we used an optimization algorithm appropriate for FIS design prob lems, namely the Genetic Algorithm (GA).

\subsection{GA optimal FIS (GAFIS) - step 2}

In several researches FIS settings are optimized using GA [37,38]. The FIS parameters are optimized in order to optimize the fuzzy decision making for an instantaneous power sharing. For this sake, we have sought to optimize the following parameters while keeping the chosen number and shapes of inputs and output MFs as in previous section:

- Position of the characteristic points of the input triangle MFs: indeed, the triangle shape is characterized by three peaks 

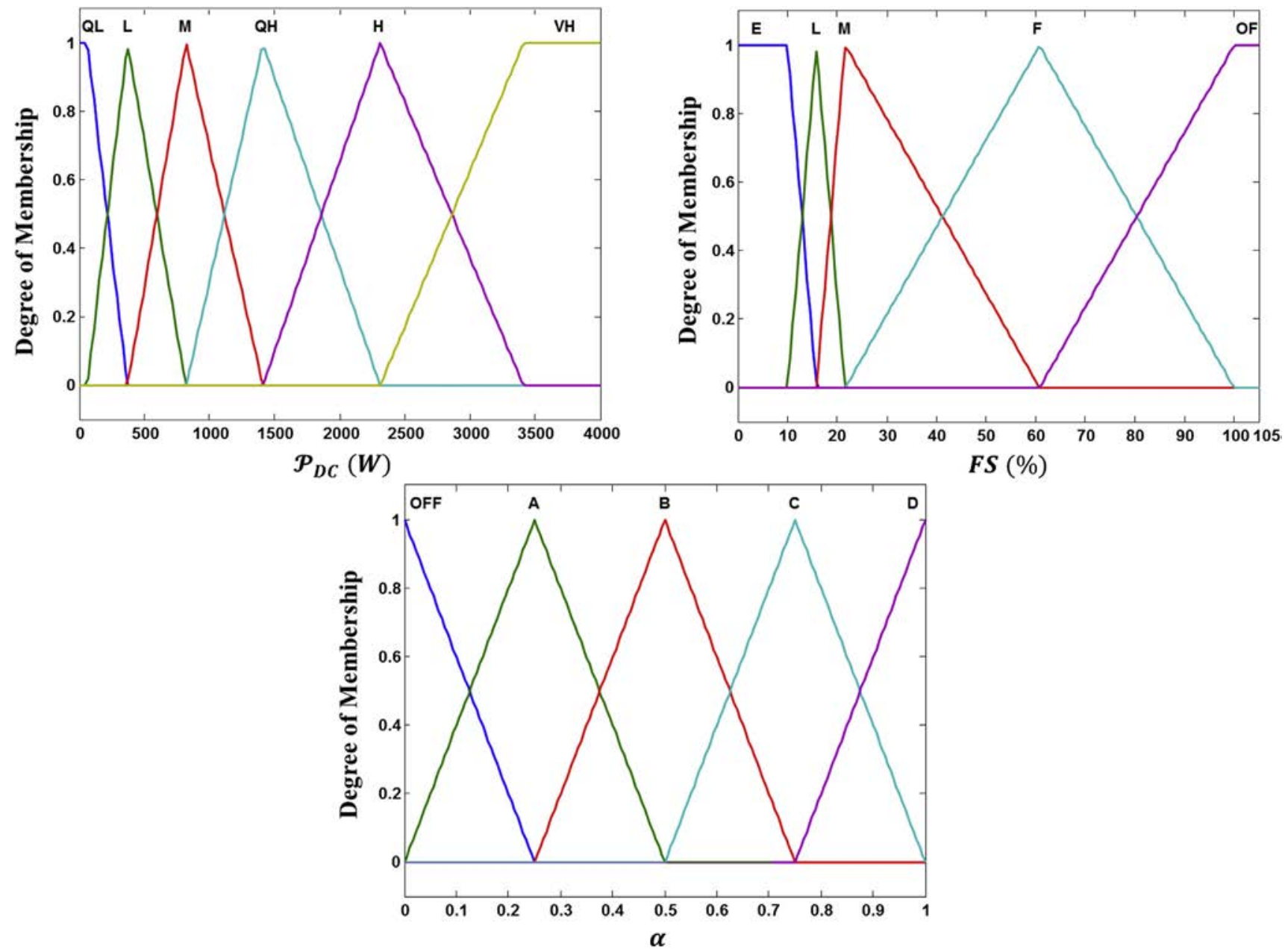

Fig. 6. Input/output membership functions.

Table 3

Numerical ranges of the inputs/outputs variables of the HMFIS.

\begin{tabular}{|c|c|c|}
\hline Symbol & Description & Numerical range \\
\hline \multicolumn{3}{|c|}{ Input $1: \mathscr{P}_{D C}$} \\
\hline QL & Quite Low & {$\left[\begin{array}{ll}0 & 370\end{array}\right]$} \\
\hline $\mathrm{L}$ & Low & {$\left[\begin{array}{ll}0 & 820\end{array}\right]$} \\
\hline M & Medium & {$\left[\begin{array}{ll}370 & 1410\end{array}\right]$} \\
\hline $\mathrm{QH}$ & Quite High & {$\left[\begin{array}{ll}820 & 2310\end{array}\right]$} \\
\hline $\mathrm{H}$ & High & {$\left[\begin{array}{ll}1410 & 3410\end{array}\right]$} \\
\hline $\mathrm{VH}$ & Very High & {$\left[\begin{array}{ll}2310 & 4000\end{array}\right]$} \\
\hline \multicolumn{3}{|c|}{ Input 2: $F S$} \\
\hline E & Empty & {$\left[\begin{array}{ll}0 & 15,85\end{array}\right]$} \\
\hline $\mathrm{L}$ & Low & {$\left[\begin{array}{ll}10 & 21,62\end{array}\right]$} \\
\hline M & Medium & {$[15,85 \quad 60,81]$} \\
\hline $\mathrm{F}$ & Full & {$[21,62100]$} \\
\hline $\mathrm{OF}$ & Overfilled & {$[60,81105]$} \\
\hline \multicolumn{3}{|c|}{ Output: $\alpha$} \\
\hline OFF & $\begin{array}{l}\text { The HPP is OFF (i.e. Pumping only) } \\
\quad>(\alpha \approx 0)\end{array}$ & {$\left[\begin{array}{ll}0 & 0,25\end{array}\right]$} \\
\hline A & Pumping with moderate desalination & {$\left[\begin{array}{ll}0 & 0,5\end{array}\right]$} \\
\hline B & Pumping and Desalination & {$[0,250,75]$} \\
\hline $\mathrm{C}$ & Pumping and Desalination & {$[0,51]$} \\
\hline $\mathrm{D}$ & Desalination only $>(\alpha \approx 1)$ & {$[0,751]$} \\
\hline
\end{tabular}

denoted respectively ' $a$ ', ' $b$ ' and ' $c$ ' (Fig. 7) where we have tried to find the optimal position of the first peak ' $a$ ' of each triangle MF of the two input variables while the two other triangle peaks ' $b$ ' and ' $c$ ' as well as the trapezoid MFs are held fixed.
Table 4

Fuzzy decision matrix of the HMFIS.

\begin{tabular}{llllllll}
\hline$\alpha$ & & $\mathscr{P}_{D C}$ & & & & & \\
\cline { 3 - 7 } & & QL & L & M & QH & H & VH \\
\hline \multirow{2}{*}{$F S$} & E & OFF & OFF & OFF & OFF & OFF & OFF \\
& L & OFF & OFF & OFF & D & B & D \\
& M & OFF & A & D & D & C & D \\
& F & OFF & D & D & D & D & D \\
& OF & OFF & D & D & D & D & D \\
\hline
\end{tabular}

- Fuzzy rules: we intend to enumerate all possible fuzzy rules and select those that contribute to increase the freshwater produc tion. We have restricted our choice to 11 fuzzy rules (those highlighted in bold and red color in Table 4) to which optimal fuzzy decision is sought. As for other rules the decision is obvious.

- Defuzzification method: there are five built in methods namely BISECTOR (bisector of area), MOM (Mean Of Maximum), LOM (Largest Of Maximum), SOM (Smallest of Maximum) and CENTROID.

All of these parameters have been coding in a 19 elements GA chromosome (Fig. 8) presented as a real vector characterizing each individual (corresponding to a single FIS): 

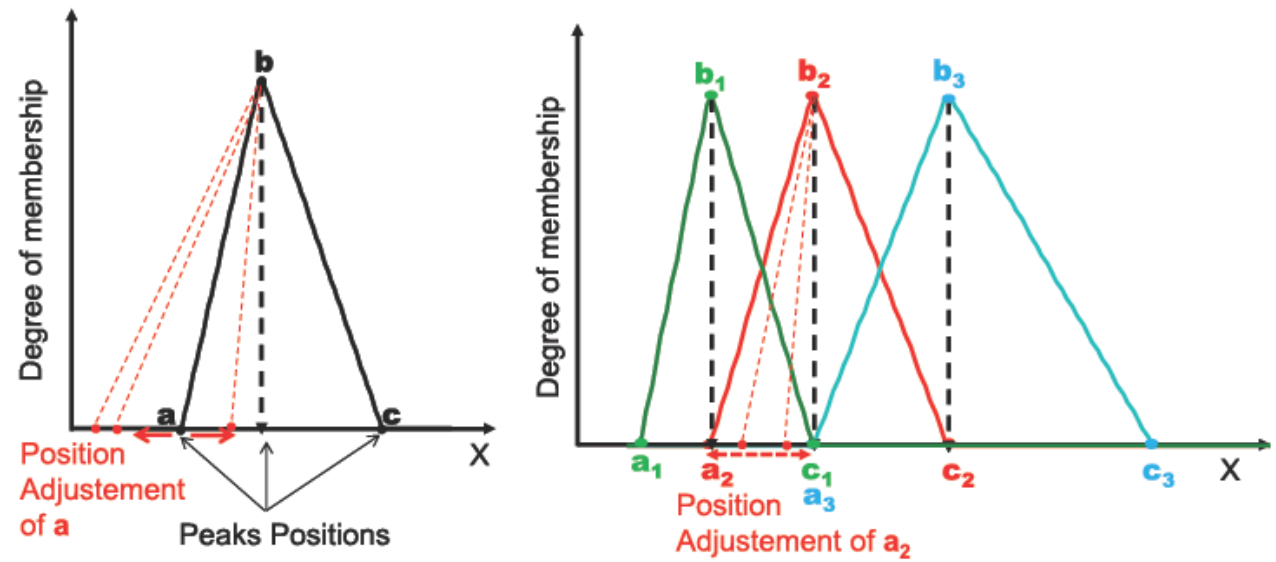

Fig. 7. Characteristic points of triangle MFs,

- 4 parameters to characterize the first input variable: $\left\{x_{i}\right\}, i$ $1: 4$,

- 3 parameters to characterize the second input variable: $\left\{y_{i}\right\}, i$ $1: 3$,

- One parameter for encoding the Defuzzication method: $\{Z\}$,

- 11 parameters for encoding the fuzzy rules to be optimized: $\left\{R_{i}\right\} ; i \quad 1: 11$

Coding of MFs parameters of the input electric power $\mathscr{P}_{D C}$ and the tank FS are illustrated in Fig. 9. These parameters as well as evaluated fitness function (2) have been chosen as maximum freshwater production attained. Using the given chromosome, a randomly created population of 200 individuals has been chosen for the initial population and the generation number has been fixed to 100 . Furthermore, the parameter values of the MFs $\left(x_{i}\right.$ and $\left.y_{i}\right)$ to be optimized have to respect the bound constraints given by (3) while respecting the given order by (4). This enables to restrict the number of solutions by rejecting non feasible ones leading to a rapid convergence of the GA. For the GA, we used the Global Optimization Toolbox available in Matlab software. We have used classical crossover, mutation and selection formulation and probability.

$f_{\text {fitness }} \int_{t=0}^{t_{\text {fnsh }}} Q_{\text {freshwater }}[t] d t$

$\left\{\begin{array}{c}a_{i} \leq x_{i} \leq b_{i} ; \quad i \quad 1: 4 \\ a_{i} \leq y_{i} \leq b_{i} ; \quad i \quad 1: 3 \\ 1 \leq Z \leq 5 \\ 1 \leq R_{i} \leq 5 ; \quad i \quad 1: 11\end{array}\right.$

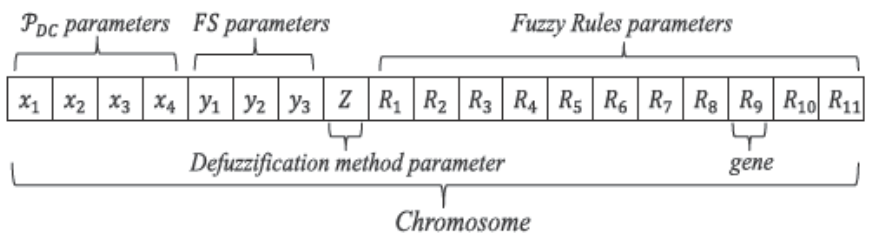

Fig. 8. A chromosome including the all FIS parameters. $\left\{\begin{array}{c}a_{i}<b_{i}<c_{i} \\ a_{i}<a_{i+1}<c_{i} \\ b_{i}<b_{i+1} \\ c_{i}<c_{i+1}\end{array}\right.$

The offline optimization of the FIS needs a prior knowledge of the input power profile. Once the optimized FIS (GAFIS) is obtained, it will be used in the FLEMS as the fuzzy decision maker for the real time approach without prior knowledge of the input power profile. The effectiveness of the proposed approach has been checked through a series of simulations for the FLEMS.

\subsection{Optimization and simulation results}

The simulation of the proposed EMS has been accomplished using the real data of PV Wind power generation recorded every hour from January to December 2007 of a region in Southeast Tunisia: Djerba Midoun (Fig. 10). The GA optimization has been performed on a daily power profile but results have been analyzed on different power profiles (daily and weekly (Fig. 11) and seasonal profiles (Fig. 14)). All simulations have been performed by means of Matlab Software using the described parameters below (Table 5) where the considered sampling period is $2.5 \mathrm{~min}$ (i.e. the sampling period is $T_{s} \quad 2.5 \times 60 \quad 150 \mathrm{~s}$ ). Indeed, an interpolation has been performed on the recorded power profile in order to modify the sampling period $\left(T_{s} \quad 1 \mathrm{~h}\right)$ which represents a long time interval for the EMS. It should be noted that during simulations we have considered two RO membranes. Table 6 shows the optimized fuzzy rules and Fig. 12 shows the two inputs MFs obtained by the GA optimization. The optimized Defuzzification method for our case is set to BISECTOR method instead of the Centroid method.

As it can be seen, there is no big difference between the initial and the optimized MFs of the first input $\left(\mathscr{P}_{D C}\right)$ except the fuzzy subset "M" (Medium) whose MF's location has notably shifted to the right. However, the MFs of the second input (FS) have all moved their initial locations to the right, particularly the fuzzy subset " $F$ " (Full). Moreover, the initial rule base has totally changed after the GA optimization so as the given power can be shared between the two motor pumps for water pumping and desalination simulta neously. For instance, when the power generation is Medium (denoted "M") and if the amount of the stored water is Medium (denoted "M"), therefore the system must desalinate water and simultaneously do pumping moderately instead of desalting water thoroughly in the case of the initial rule base (Table 4). This leads to the following optimized rule: 

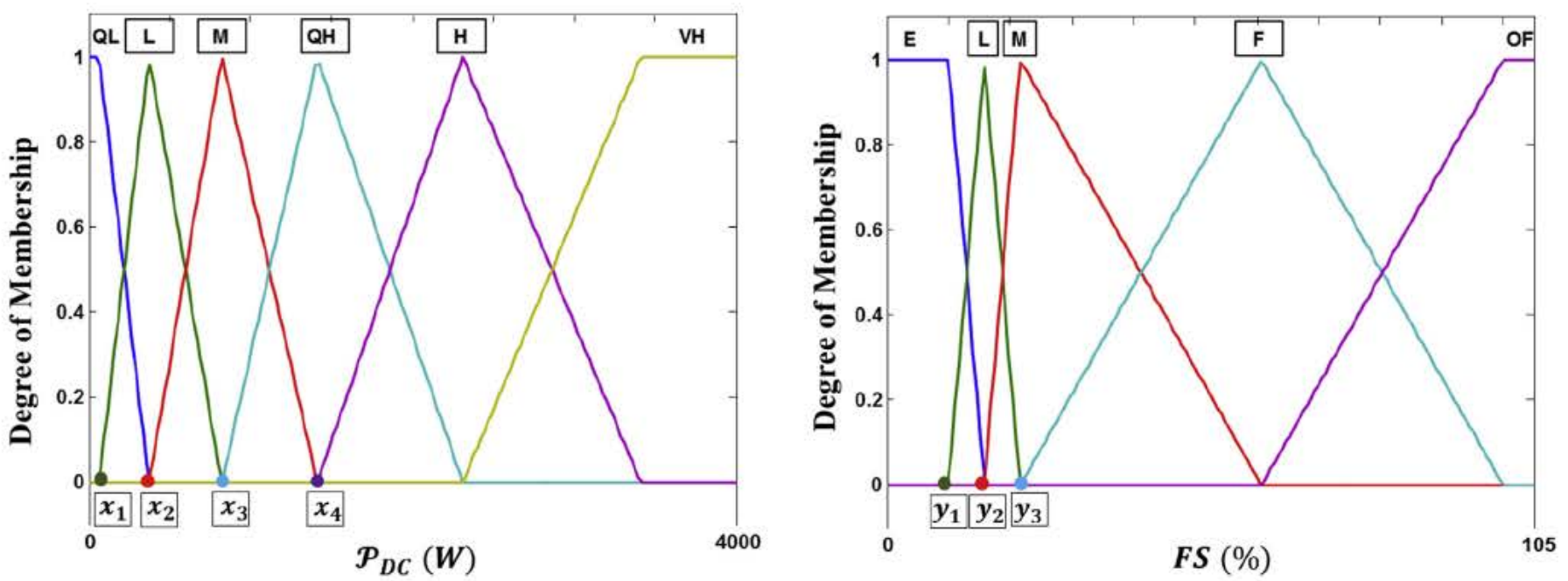

Fig. 9. Coding parameters of inputs MFs.

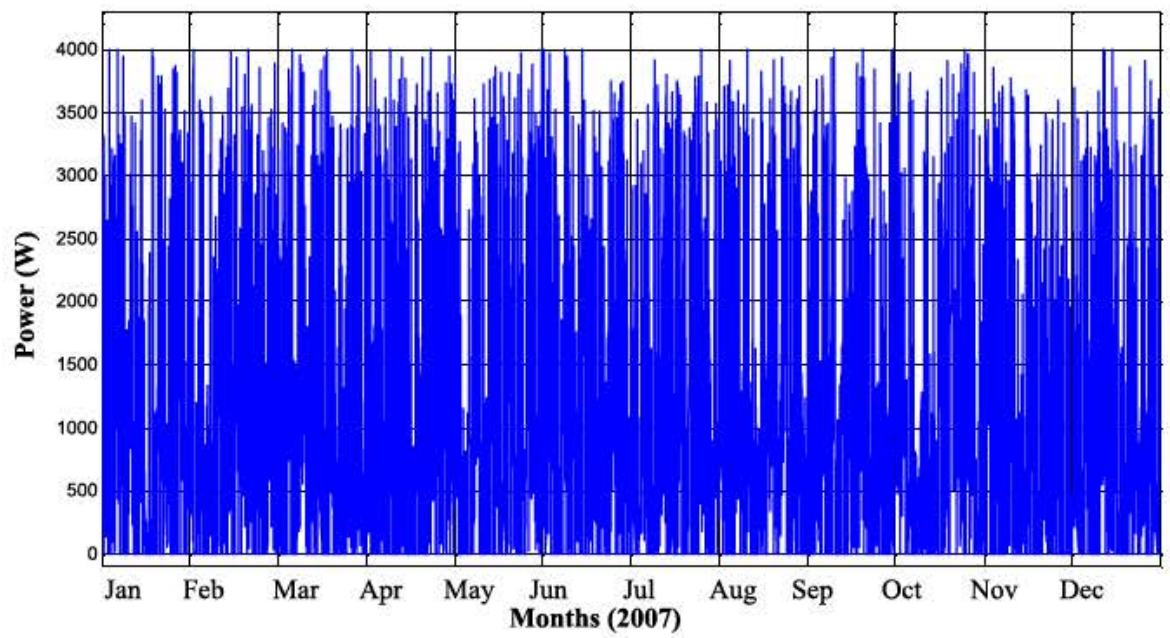

Fig. 10. Total generated power profile.

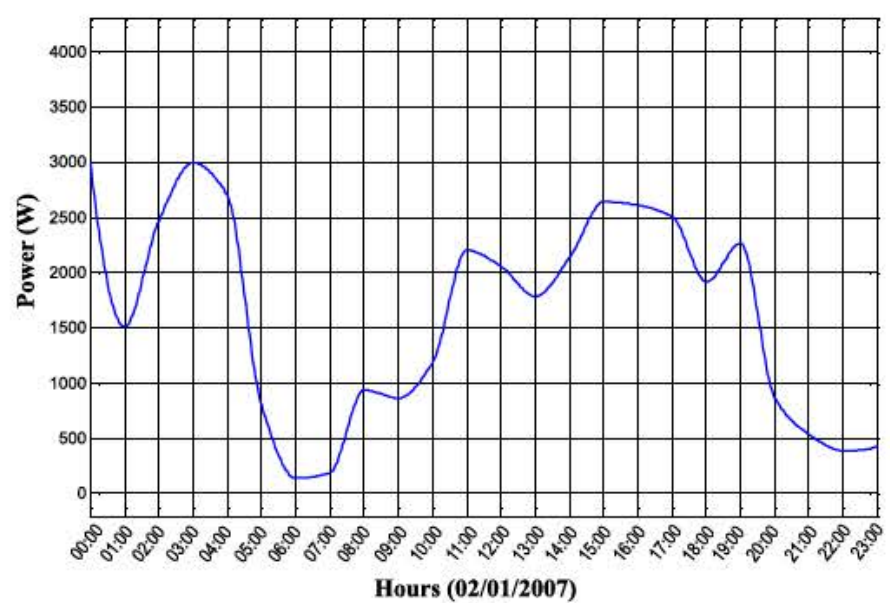

(a)

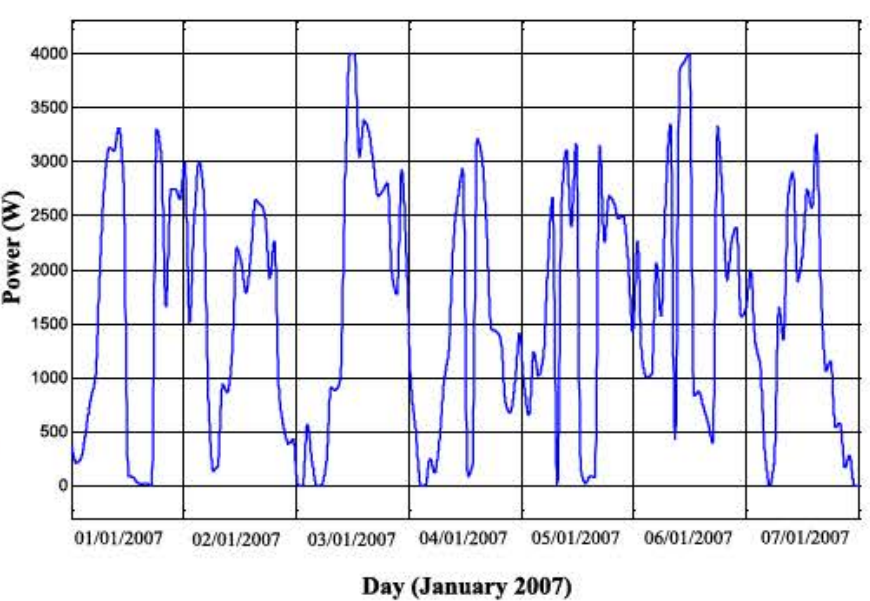

(b)

Fig. 11. Daily (a) and weekly (b) power profiles. 

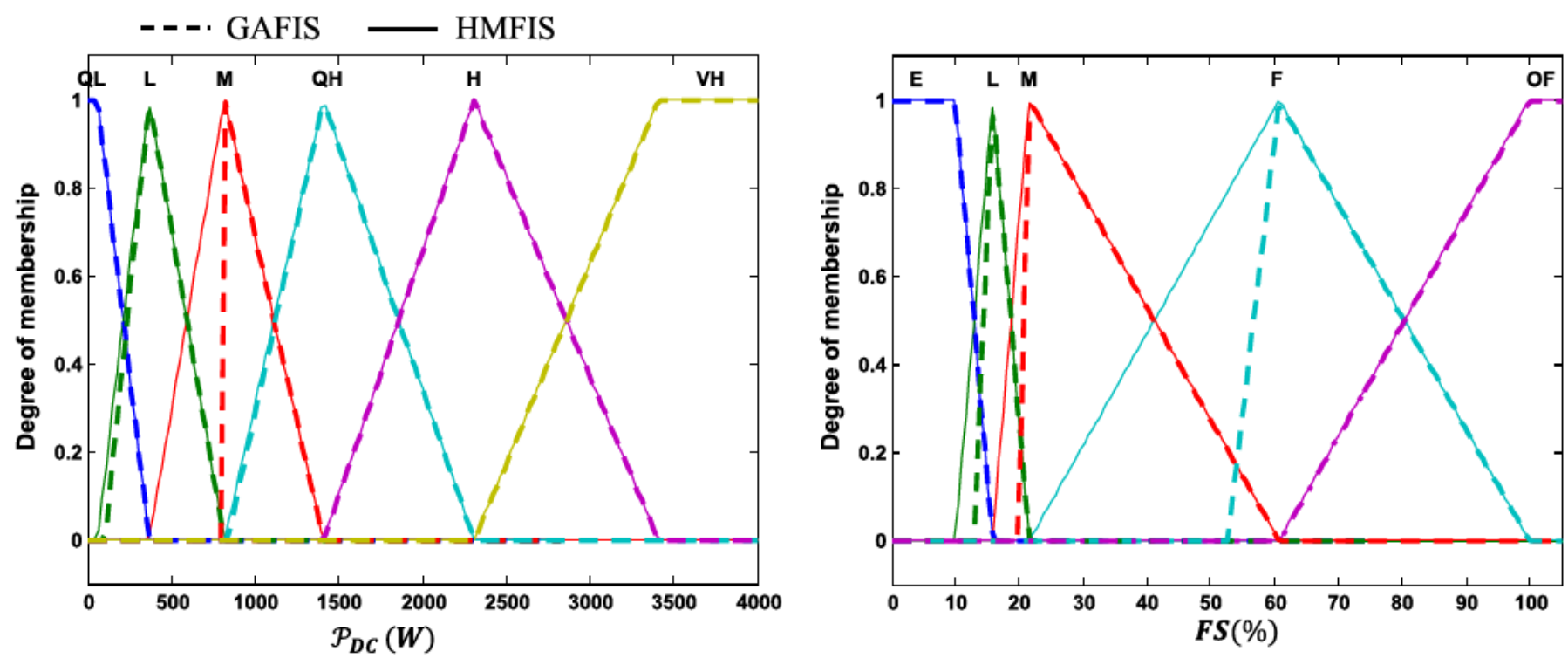

Fig. 12. Memebership functions of the two inputs for the GAFIS and HMFIS.
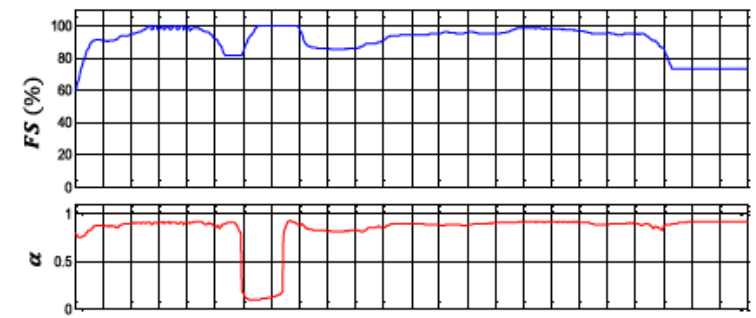

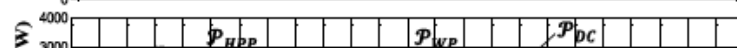
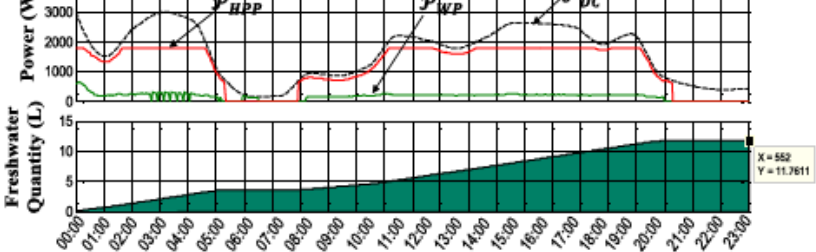
Hours (02/01/2007)

(a)
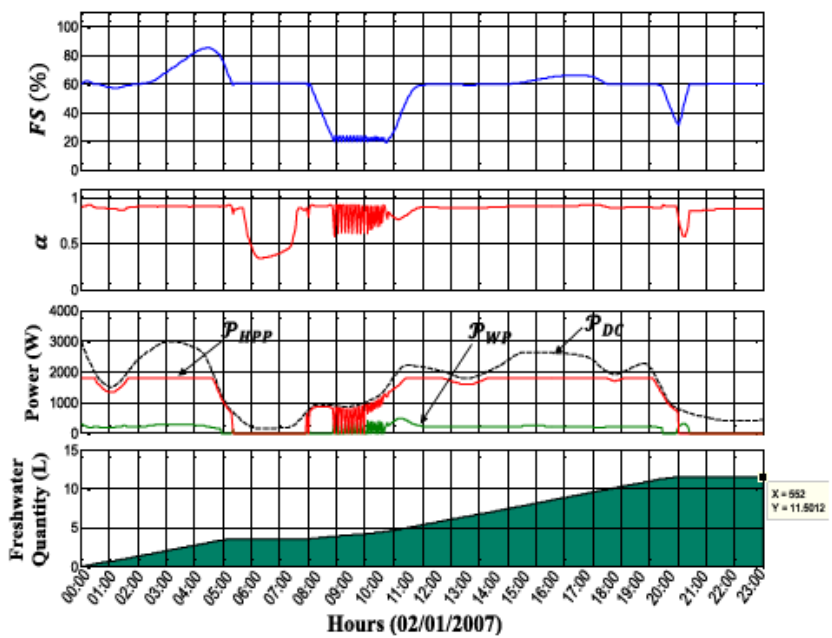

(b)
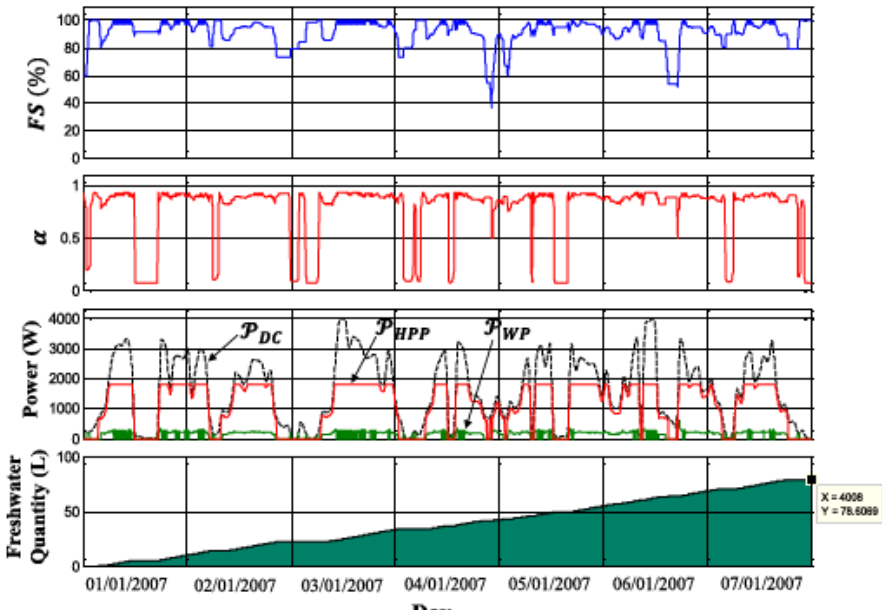

(c)
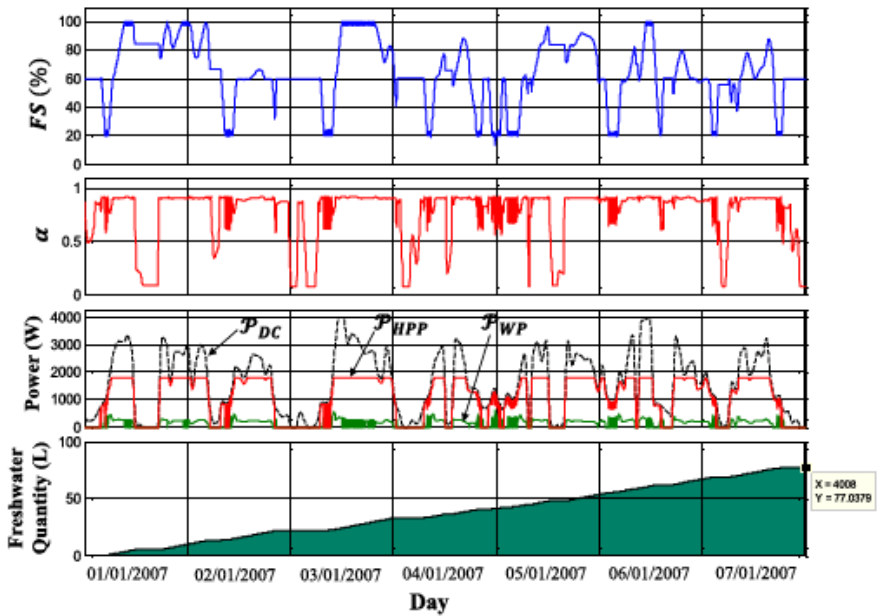

(d)

Fig. 13. Simulation results of the FLEMS using the HMFIS and the GAFIS. 

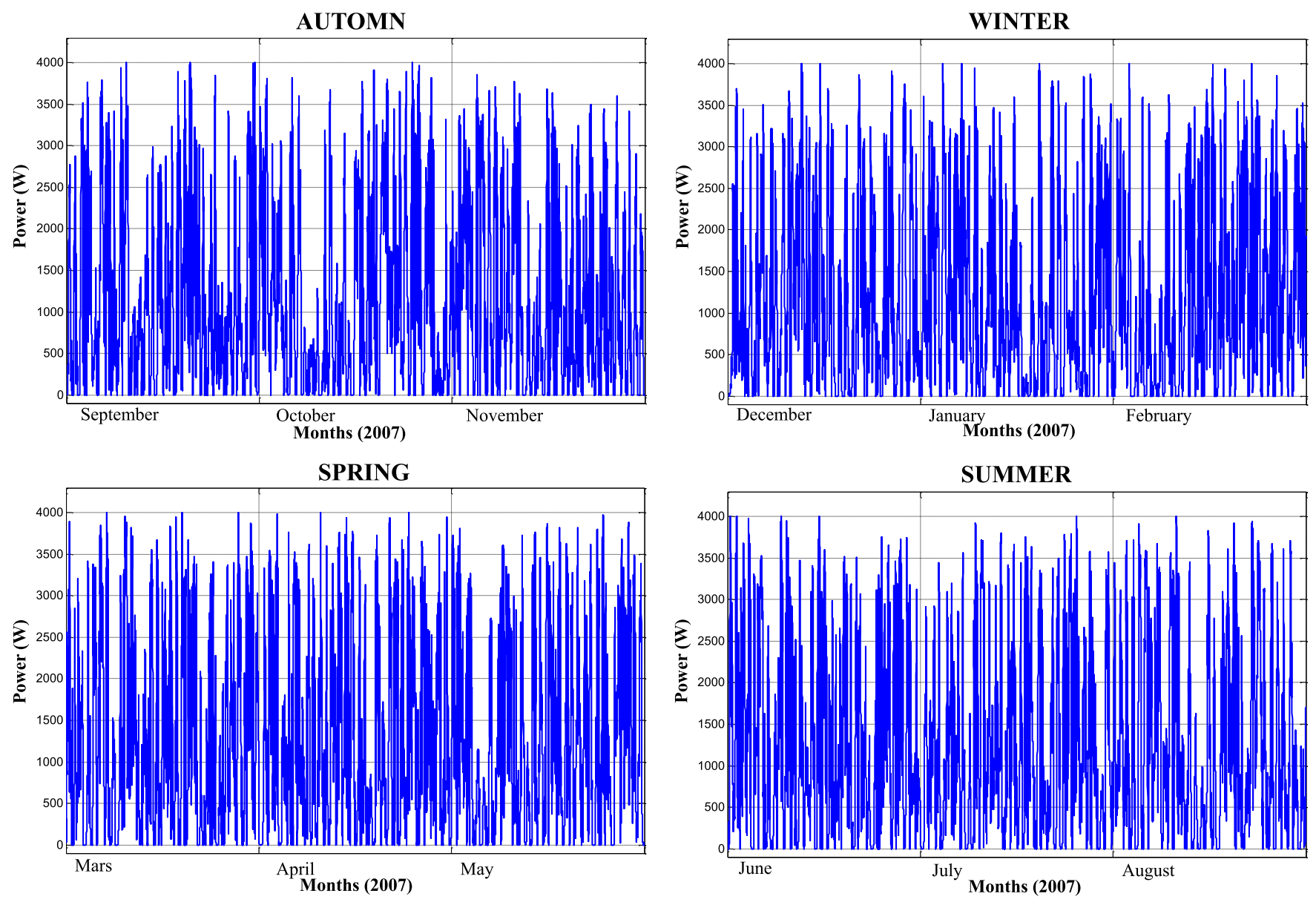

Fig. 14. Seasonal power profiles.

Table 5

Simulation parameters.

\begin{tabular}{llll}
\hline Symbol & Description & Value & Unit \\
\hline$k_{1}$ & Number of samples in one day & 553 & samples \\
$k_{2}$ & Number of samples in one week & 4009 & samples \\
$k_{3}$ & Number of samples in a year & 210217 & samples \\
$T_{s}$ & Sampling period & 150 & $\mathrm{~s}$ \\
$T_{t}$ & Total time for one day & 82950 & $\mathrm{~s}$ \\
$F S_{\text {max }}$ & Maximum Tank FS & 100 & $\%$ \\
$F S_{\text {min }}$ & Minimum Tank FS & 10 & $\%$ \\
$F S_{0}$ & Initial Tank FS & 60 & $\%$ \\
$\mathscr{P}_{\text {HPPmin }}$ & Minimum HPP power & 620 & $\mathrm{~W}$ \\
$\mathscr{P}_{\text {HPPax }}$ & Maximum HPP power & 1800 & $\mathrm{~W}$ \\
$\mathscr{P}_{\text {WPmin }}$ & Minimum WP power & 120 & $\mathrm{~W}$ \\
$\mathscr{P}_{\text {WPmax }}$ & Maximum WP power & 1020 & $\mathrm{~W}$ \\
$\mathscr{P}_{D \text { Cmax }}$ & Maximum generated DC power & 4000 & $\mathrm{~W}$ \\
\hline
\end{tabular}

IF $\mathscr{P}_{D C}$ is M AND FS is M THEN $\alpha$ is B.

Extending this reasoning to the other cases leads to the opti mized rule base presented in Table 6. This can be tangibly seen through simulation results of the optimized FIS (GAFIS) applied in the FLEMS.

Some of simulation results of the FLEMS using the obtained GAFIS are illustrated in Fig. 13. We have shown also results of the FLEMS using the HMFIS developed in the previous section for comparison purposes. We can see in these figures a daily evolution of the system behavior for one day in Fig. 13-a) and -b) and for 7 consecutive days in Fig. $13-\mathrm{c}$ ) and $-\mathrm{d}$ ). So, in these simulations we
Table 6

Fuzzy decision matrix of the GAFIS

\begin{tabular}{llllllll}
\hline$\alpha$ & & $\mathscr{P}_{D C}$ & & & & & \\
\cline { 3 - 7 } & & QL & L & M & QH & H & VH \\
\hline FS & E & OFF & OFF & OFF & OFF & OFF & OFF \\
& L & OFF & OFF & A & A & C & D \\
& M & OFF & D & B & B & B & D \\
& F & OFF & D & C & C & C & D \\
& OF & OFF & D & D & D & D & D \\
\hline
\end{tabular}

QL: Quite Low.

L: Low.

M: Medium.

QH: Quite High.

$\mathrm{H}$ : High.

VH: Very High E: Empty.

F: Full.

OF: Overfilled.

have presented the storage tank FS evolution, the instantaneous power sharing factor $\alpha$, the input power profile $\mathscr{P}_{D C}$ and the assigned electric power of each motor pump $\left(\mathscr{P}_{H P P}, \mathscr{P}_{W P}\right)$ following the instantaneous EMS inputs values $\left(F S[t], \mathscr{P}_{D C}[t]\right)$, and the freshwater quantity during the studied period. As it can be seen in Fig. 13-a) the filling state profile of the storage tank is close to $100 \%$ when applying the GAFIS, but it is close to $60 \%$ when applying the HMFIS (Fig. 13-b)) during the day under study. Then, during the studied week the filling state profile still being close to $100 \%$ when 
Table 7

Simulation results of the FLEMS for one week power profile.

\begin{tabular}{llll}
\hline & GAFIS & HMFIS & Gain \\
\hline Freshwater $\left(\mathrm{m}^{3}\right)$ & $\mathbf{7 8 , 7}$ & 77,1 & $2,10 \%$ \\
Brackish water $\left(\mathrm{m}^{3}\right)$ & $\mathbf{2 , 0 8}$ & 1,23 & $68,62 \%$ \\
$E_{c}(\mathrm{kWh})$ & $\mathbf{2 0 7 , 7 3}$ & 204,96 & $1,33 \%$ \\
$E_{n c}(\mathrm{kWh})$ & $\mathbf{5 9 , 7 3}$ & 62,49 & $4,62 \%$ \\
\hline
\end{tabular}

Table 8

Simulation results of the FLEMS for the daily power profile.

\begin{tabular}{llll}
\hline & GAFIS & HMFIS & Gain \\
\hline Freshwater $\left(\mathrm{m}^{3}\right)$ & $\mathbf{1 1 , 8}$ & 11,5 & $2,50 \%$ \\
Brackish water $\left(\mathrm{m}^{3}\right)$ & $\mathbf{1 , 4 7}$ & 1,26 & $16,92 \%$ \\
$E_{c}(\mathrm{kWh})$ & $\mathbf{3 1 , 2 6}$ & 30,65 & $1,95 \%$ \\
$E_{n c}(\mathrm{kWh})$ & $\mathbf{5 , 9 2}$ & 6,53 & $10,3 \%$ \\
\hline
\end{tabular}

applying the GAFIS (Fig. 13-c)), but it strongly varies within a range of $20 \%-100 \%$ with an average value of $60 \%$ when applying the HMFIS (Fig. 13-d)). That is to say, the obtained GAFIS tries all the time to keep full the storage tank by pumping much more brackish water compared with the HMFIS (for instance, water gain of $68.62 \%$ during one week in Table 7). This enables on the one hand to take advantage as much as possible of the generated power (see the consumed and non consumed energy $E_{c}, E_{n c}$ in Tables 7 and 8) for simultaneously desalination and pumping water and, on the other hand to acquire much more additional free hydraulic energy. This leads to improve the system energy efficiency as well as to increase the freshwater production of the RO membranes as aforemen tioned (for instance, freshwater gain of $2.5 \%$ during one week in Table 7). However, with HMFIS the storage tank emptied and filled several times during the studied week. That is to say, the water level in the storage tank increases and decreases cyclically so as we cannot take advantage all the time of the additional free hydraulic energy which in turn increases and decreases accordingly. This leads to produce less freshwater quantity compared with the GAFIS.

The objective of this work is to make an online fuzzy decision that should be robust in case of power profile that seems likely to be different to the one studied offline. So, in order to check the robustness of the obtained GAFIS in terms of power profile, we have tested this one on four different seasonal power profiles (Fig. 14).

Indeed, each power profile becomes unknown for the FLEMS because the invoked GAFIS has been identified for a daily power profile (Fig. 11-a)). Comparison results are given in Table 9. When applying the GAFIS for different input power profiles better results are always obtained compared to the HMFIS results. In addition to freshwater production, we can note in Table 9 higher brackish water quantity, higher consumed energy and less energy loss when using GAFIS. That is to say the latter tries during each studied period as aforementioned to keep the storage tank in a high filling state which represents gravitational water storage, while making the most of the available generated power.

To conclude, the optimized FIS design with its optimized rule base enabled the desalination system to take full advantage of the available generated power through pumping much more brackish water than the HMFIS design allowing increasing the brackish water storage. These findings demonstrate the usefulness and effectiveness of GA optimization approach as an optimization tool for FIS designing.

\section{Conclusion}

In this paper a specific class of standalone battery less PV/Wind BWRO desalination system has been presented. The particularity of the proposed architecture is to substitute the electrochemical storage, basically integrated in such an autonomous system, by utilizing hydraulic storage in tanks when renewable energy is available. This issue has been addressed through a specific and optimized water and power flows management strategy based on the fuzzy logic theory. The latter has been chosen since linguistic rules can significantly simplify the control and management of complex energy systems using a few linguistic variables. The major scientific challenge that this work contributes to rise is the devel opment of optimized EMS, which could work in real time for such an autonomous system especially dedicated to remote commu nities. The sought objective through the developed EMS is to pro duce freshwater as much as possible while taking advantage of the available electric power offered along wind speed and sun irradi ation conditions. So, according to the input electric power and the current tank filling state $F S$, fuzzy rules have been used to identify the instantaneous power sharing between the two motor pumps so that to maximize freshwater production according the available generated power. The FIS design has been performed based on two steps: in the first one, based on our experience we have chosen the inputs/outputs MFs (number, type, location and mapping) and set the initial rule base and the Defuzzification method as well. In the second step an off line GA optimization has been applied on the HMFIS design based on evaluation criterion to derive the optimized FIS parameters. Compared with the HMFIS design, the optimized one enabled the EMS to manage the water/power flows while taking full advantage of the available generated power so that the energy efficiency of the desalination system was tangibly improved and the seasonal freshwater production was increased to about $3.3 \%$ in autumn for instance as well as the pumped brackish water was increased from $16.7 \%$ in autumn to $63 \%$ in summer.

Furthermore, regarding the system behavior following the optimization process a relevant conclusion can be highlighted: when adjusting the HMFIS parameters the human reasoning (rule based logic) pushes us to favor water desalination over water pumping (which is the obvious thinking) by addressing the most of energy to the desalination pump (HPP). Unfortunately, that seems to be not the best decision over the studied period. In the other side, machine reasoning (based on machine learning by testing several combinations of FISs) leads to the best performances although it is likely to be illogic at first glance (allowing much more pumping). Such a system behavior has emphasized the importance of the gravitational storage water. It is worth mentioning that the

Table 9

Comparison results obtained with HMFIS- and GAFIS-EMS tested for different seasonal power profiles.

\begin{tabular}{|c|c|c|c|c|c|c|c|c|c|c|c|c|}
\hline & \multicolumn{3}{|c|}{ Autumn } & \multicolumn{3}{|l|}{ Winter } & \multicolumn{3}{|l|}{ Spring } & \multicolumn{3}{|c|}{ Summer } \\
\hline & GAFIS & HMFIS & Gain & GAFIS & HMFIS & Gain & GAFIS & HMFIS & Gain & GAFIS & HMFIS & Gain \\
\hline Freshwater $\left(\mathrm{m}^{3}\right)$ & 746,96 & 722,63 & $3,3 \%$ & 755,68 & 731,76 & $3,2 \%$ & 817,24 & 795 & $2,8 \%$ & 789,29 & 772,35 & $2,2 \%$ \\
\hline Brackish water $\left(\mathrm{m}^{3}\right)$ & 1,49 & 1242 & $16,7 \%$ & 1897 & 0,747 & $60,6 \%$ & 1985 & 1242 & $37,5 \%$ & 1889 & 0,699 & $63 \%$ \\
\hline$E_{c}(\mathrm{kWh})$ & 1939,1 & 1898,1 & $2,1 \%$ & 1963,5 & 1924,8 & $2 \%$ & 2129,5 & 2094,5 & $1,7 \%$ & 2070,9 & 2028,3 & $2,1 \%$ \\
\hline$E_{n c}(\mathrm{kWh})$ & 625,92 & 666,95 & $6.6 \%$ & 618,83 & 657,51 & $6,3 \%$ & 688,41 & 723,43 & $5,1 \%$ & 683,94 & 726,58 & $6,3 \%$ \\
\hline
\end{tabular}


machine learning based reasoning can be a first step to study the so called Smart EMS versus rule based EMS.

Implementing an autonomous water desalination system pow ered by RESs in remote areas is still being a problematic issue that needs to be carefully addressed to guarantee freshwater supply. Energy management represents the major problem of such a sys tem and the proposed approach in this paper could be used to solve the problem in real time, but an experimental validation needs to be carried out on the experimental test bench to confirm the simulation results and the feasibility of the proposed FLEMS.

\section{Acknowledgments}

This work was supported by the Tunisian Ministry of Higher Education and Research under Grant LSE-ENIT LR 11 ES15 and the European project "ERANETMED EDGWISE" ID 044".

\section{References}

[1] World Widelife Fund for nature. Living planet report. 2010.

[2] World Widelife Fund. Threats, water scarcity. http://www.worldwildlife.org/ threats/water-scarcity/ [Accessed 09 Febrary 2018].

[3] Hoekstra AY, Mekonnen MM, Chapagain AK. Ruth E. Mathews, Brian D. Richter. Global monthly water scarcity: blue water footprints versus blue water availability. PLoS One 2012;7:32688

[4] Ghermandi A, Messalem R. Solar-driven desalination with reverse osmosis: the state of the art. Desalination and Water Treatment 2009;7:285 96.

[5] Eltawil MA, Zhengming Z, Yuan L. A review of renewable energy technologies integrated with desalination system. Renew Sustain Energy Rev 2009;13: 2245 62. https://doi.org/10.1016/j.rser.2009.06.011.

[6] Ghaffour N, Missimer Th M, Amy GL. Technical review and evaluation of the economics of water desalination: current and future challenges for better water supply sustainability. Desalination 2013;309:197 207. https://doi.org/ 10.1016/j.desal.2012.10.015.

[7] Kaldellis JK, Kavadias KA, Kondili E. Renewable energy desalination plants for the Greek islands technical and economic considerations. Desalination 2004;170:187 203. https://doi.org/10.1016/j.desal.2004.01.005.

[8] Thiam D-R. Renewable decentralized in developing countries: appraisal from microgrids project in Senegal. Renew Energy 2010;35:1615 23. https:// doi.org/10.1016/j.renene.2010.01.015.

[9] Gude VG, Nirmalakhandan N, Deng S. Renewable and sustainable approaches for desalination. Renew Sustain Energy Rev 2010;14:2641 54. https:// doi.org/10.1016/j.rser.2010.06.008.

[10] Ranaboldo M, Lega BD, Ferrenbach DV, Ferrer-Martí L, Moreno RP, GarcíaVilloria A. Renewable energy projects to electrify rural communities in Cape Verde. Appl Energy 2014;118:280 91. https://doi.org/10.1016/ j.apenergy.2013.12.043.

[11] Thomson M, Miranda M, Gwillim J, Rowbottom A, Draisey I. Batteryless photovoltaic reverse-osmosis desalination system. 2001.

[12] de la Nuez Pestana I, Javier García Latorre F, Argudo Espinoza C, Gómez Gotor A. Optimization of RO desalination systems powered by renewable energies. Part I: wind energy. Desalination 2004;160:293 9. https://doi.org/ 10.1016/S0011-9164(04)90031-8.

[13] Elahian S, Abrishamifar A, Ale-Ahmad A. Optimal fuzzy logic controller for energy management in fuel cell hybrid electric vehicle. Cyber journals: multidisciplinary journals in science and technology. Journal of Selected Areas in Renewable and Sustainable Energy 2012.

[14] Neffati A, Guemri M, Caux S, Fadel M. Energy management strategies for multi source systems. Elec Power Syst Res 2013;102:42 9. https://doi.org/10.1016/ j.epsr.2013.03.008.

[15] Gao D, Jin Z, Lu Q. Energy management strategy based on fuzzy logic for a fuel cell hybrid bus. J Power Sources 2008;185:311 7. https://doi.org/10.1016/ j.jpowsour.2008.06.083.

[16] He Z, Mollet F, Saudemont CH, Robyns B. Experimental validation of energy storage system management strategies for a local DC distribution system of more electric aircraft. IEEE Trans Ind Electron 2010;57:3905 16. https:// doi.org/10.1109/TIE.2010.2046575.

[17] Buzilat Pankovits PV, Abbes D, Saudemont Ch, Moumniabdou O, Pouget J, Robyns B. Energy management multi-criteria design for hybrid railway power substations. In: The 11th international conference on modeling and simulation of electric machines, converters and systems (ELECTRIMAC), 19-22 may: 2014 [Valencia, Spain]

[18] García P, Torreglosa JP, Fernández LM, Jurado Fr. Optimal energy management system for stand-alone wind turbine/photovoltaic/hydrogen/battery hybrid system with supervisory control based on fuzzy logic. Int J Hydrogen Energy 2013;38:14121 368. https://doi.org/10.1016/j.ijhydene.2013.08.106.

[19] Kyriakarakos G, Dounis AI, Arvanitis KG, Papadakis G. A fuzzy logic energy management system for polygeneration microgrids. Renew Energy 2012: 315 27. https://doi.org/10.1016/j.renene.2011.11.019. E:|dossier_thèse_ines ben ali|Travaux_Recherche_2016-2017|revu_N1|soumission des articles|energy journal $\backslash 4141$.

[20] M. EL Mokadem, V. Courtecuisse, Ch Saudemont, B. Robyns, J. Deuse. Fuzzy logic supervisor based primary frequency control experiments of a variable speed wind generator. IEEE Trans Power Syst 2009;24:407 417. https:// doi.org/10.1109/TPWRS.2008.2007005

[21] Farhat M, Barambones O, Sbita L. Efficiency optimization of a DSP-based standalone PV system using a stable single input fuzzy logic controller. Renew Sustain Energy Rev 2015:907 20. https://doi.org/10.1016/ j.rser.2015.04.123. E:|dossier_thèse_ines ben ali|Travaux_Recherche_20162017\revu_N1\soumission des articles/energy journal|4949.

[22] Sallem S, Chaabene M, Kamoun MBA. Optimum energy management of a photovoltaic water pumping system. Energy Convers Manag 2009;50: 2728 31. https://doi.org/10.1016/j.enconman.2009.06.036.

[23] Abdul-Fattah AF. Engineering management of desalination plants in Saudi Arabia using fuzzy decision analysis. Desalination 1981;37:343 50. https:/| doi.org/10.1016/S0011-9164(00)88657-9.

[24] Fritzmann C, Lowenberg J, Wintgens T, Melin T. State-of-the-art of reverse osmosis desalination. Desalination 2007;216:1 76. https://doi.org/10.1016 j.desal.2006.12.009.

[25] Ghaffour N, Lattemann S, Missimer Th, Ng KC, Sinha S. G. Amy. Renewable energy-driven innovative energy-efficient desalination technologies. App Energy 2014;136:1155 65. https://doi.org/10.1016/j.apenergy.2014.03.033.

[26] Mbarga AA, Song L, Williams WR, Rainwater K. Integration of renewable energy technologies with desalination. Current Sustainable/Renewable Energy Reports 2014;1:11 8. https://doi.org/10.1007/s40518-013-0002-1.

[27] Ghaffour N, Bundschuh J, Mahmoudi H, Goosen MFA. Renewable energy driven desalination technologies: a comprehensive review on challenges and potential applications of integrated systems. Desalination 2015;356:94 114 https://doi.org/10.1016/j.desal.2014.10.024.

[28] Tzen E, Theofilloyianakos D, Kologios Z. Autonomous reverse osmosis units driven by RE sources experiences and lessons learned. Desalination 2008;221: 29 36. https://doi.org/10.1016/j.desal.2007.02.048.

[29] Roboam X, Sareni B, Nguyen DT, Belhadj J. Optimal system management of a water pumping and desalination process supplied with intermittent renewable sources. IFAC Proceedings Volumes 2012;45:369 74. https://doi.org/ 10.3182/20120902-4-FR-2032.00066.

[30] Al-Nory M, El-Beltagy M. An energy management approach for renewable energy integration with power generation and water desalination. Renew Energy 2014;72:377 85. https://doi.org/10.1016/j.renene.2014.07.032.

[31] Guo L, Liu W, Li X, Liu Y, Jiao B, Wang W, Wang Ch, Li F. Energy management system for stand-alone wind-powered-desalination microgrid. IEEE Transactions on Smart Grid 2014;(7):1079 87. https://doi.org/10.1109/ TSG.2014.2377374.

[32] Kyriakarakos G, Dounis AI, Arvanitis KG, Papadakis G. Design of a Fuzzy Cognitive Maps variable-load energy management system for autonomous PV-reverse osmosis desalination systems: a simulation survey. Appl Energy 2017;187:575 84. https://doi.org/10.1016/j.apenergy.2016.11.077.

[33] Ben Ali I, Turki M, Belhadj J, Roboam X. Using quasi-static model for water power management of a stand-alone wind/photovoltaic/BWRO desalination system without batteries. In: The 7th international renewable energy congress (IREC), 22-24 March; 2016. https://doi.org/10.1109/ IREC.2016.7478871. Hammamet Tunisie.

[34] Ben Ali I, Turki M, Belhadj J, Roboam X. Fuzzy logic based power management for reverse osmosis desalination process fed by intermittent hybrid renewable source. In: The 11th international conference on modeling and simulation of electric machines, converters and systems (ELECTRIMAC), 19-22 may; 2014 [Valencia, Spain].

35] Ben Ali I, Turki M, Belhadj J, Roboam X. Systemic design of a reverse osmosis desalination process powered by hybrid energy system: bond graph modeling approach \& experimental validation. In: The $1^{\text {st }}$ international conference on electrical sciences and technologies in Maghreb (CISTEM), 3-6 November; 2014. https://doi.org/10.1109/CISTEM.2014.7076941. Tunis-Tunisie.

[36] Ben Ali I, Turki M, Belhadj J, Roboam X. Energy management of reverse osmosis desalination process powered by a hybrid renewable energy source. In: The $16^{\text {th }}$ IEEE Mediterranian electrotechnical conference (MELECON), 25 28 March; 2012. Yasmine Hammamet-Tunisia, https://doi.org/10.1109/ MELCON.2012.6196551.

[37] Pham DT, Karaboga D. Optimum design of fuzzy logic controllers using genetic algorithms. J Syst Eng 1991;1:114 8.

[38] McCormick Simultaneous design of membership functions and rule sets for fuzzy controllers using genetic algorithmsHomaifar Abd, editor. IEEE Trans Fuzzy Syst 1995;3:129 39. https://doi.org/10.1109/91.388168. 